\title{
COMPETITIVIDADE DAS NAÇÕES: ANÁLISE DA MÉTRICA UTILIZADA PELO WORLD ECONOMIC FORUM
}

\author{
COMPETITIVENESS OF NATIONS: REVIEW OF THE METRIC USED BY THE WORLD \\ ECONOMIC FORUM
}

COMPETITIVIDAD DE LAS NACIONES: ANÁLISIS DE LA MÉTRICA UTILIZADA POR EL WORLD ECONOMIC FORUM

\section{RESUMO}

A competitividade das nações é assunto relevante aos tomadores de decisão quando se trata da escolha do país que poderá render melhores resultados aos investimentos. Nessa linha, busca-se analisar a métrica de competitividade dos países utilizando conceitos da estatística multivariada, a fim de simplificar e evitar resultados dúbios quanto ao tema. Para isso, utilizaram-se as bases de dados de 2010 publicadas pelo World Economic Forum (WEF), que utiliza 12 pilares para estabelecer a condição competitiva de 133 países. Verificou-se que a métrica utilizada pelo WEF é redundante, já que utiliza pilares que representam o mesmo constructo. Verificou-se, ainda, que a prontidão tecnológica explica a competitividade do país em $86,5 \%$ e que a combinação entre estabilidade macroeconômica, qualidade do ensino superior e sofisticação dos negócios eleva esse percentual para 95,7\%.

PALAVRAS-CHAVE Pilares da competitividade, World Economic Forum, métricas de competitividade, competitividade nacional, base da inovação.

\section{Luciano Castro de Carvalho luccar@gmail.com}

Doutorando em Administração de Empresas pela Escola de Administração de Empresas de São Paulo, Fundação Getulio Vargas - São Paulo - SP, Brasil

Luiz Carlos Di Serio luiz.diserio@fgv.br

Professor da Escola de Administração de Empresas de São Paulo, Fundação Getulio Vargas - São Paulo - SP, Brasil

Marcos Augusto de Vasconcellos marcos.vasconcellos@fgv.br

Professor da Escola de Administração de Empresas de São Paulo, Fundação Getulio Vargas - São Paulo - SP, Brasil

\begin{abstract}
The competitiveness of nations is a relevant matter to decision makers when it comes to choose the country which may yield better results on investment. In this trend, this study seeks to analyze the metrics of competitiveness of countries using multivariate statistical concepts in order to simplify and avoid mixed results on the subject. With such a purpose, we used the databases published by the World Economic Forum (WEF) in 2010, which uses twelve pillars to establish the competitive position of 133 countries. It was found that the metric used by the WEF is redundant since it relies on pillars that represent the same construct. It was found that Technology Readiness explains the country's competitiveness in $86.5 \%$ and that the combination of Macroeconomic Stability, Quality of Higher Education and Business Sophistication rises this percentage to $95.7 \%$.

keywords Pillars of competitiveness, World Economic Forum, competitiveness metric, national competitiveness, innovation base.

Resumen La competitividad de las naciones es un asunto relevante para los tomadores de decisión cuando se trata de la elección del país que podrá rendir mejores resultados para las inversiones. En esa línea, se busca analizar la métrica de competitividad de los países utilizando conceptos de la estadística multivariada, a fin de simplificar y evitar resultados dudosos respecto al tema. Para eso, se utilizaron las bases de datos de 2010 publicadas por el World Economic Forum (WEF), que utiliza 12 pilares para establecer la condición competitiva de 133 países. Se verificó que la métrica utilizada por el WEF es redundante, ya que utiliza pilares que representan el mismo constructo. También se verificó que la prontitud tecnológica explica la competitividad del país en 86,5\% y que la combinación entre estabilidad macroeconómica, calidad de la enseñanza superior y sofisticación de los negocios eleva ese porcentual a 95,7\%. Palabras clave Pilares de la competitividad, World Economic Forum, métricas de competitividad, competitividad nacional, base de la innovación.
\end{abstract}




\section{INTRODUÇÃo}

O grau de abertura da economia das nações e o advento da globalização têm motivado consultorias e instituições de pesquisas na análise da competitividade como um indicativo de desenvolvimento econômico. A competitividade, assim, pode estar atrelada aos fatores culturais, incentivo governamental para desenvolvimento do país, câmbio, recursos naturais, nível de educação, inovação, tecnologia e outros fatores. Nesse sentido, a análise da competitividade apresenta-se valiosa para tomadores de decisões ou investidores que buscam reconhecer países que possam conferir melhores resultados aos investimentos, em função do cenário macroeconômico.

Com vistas a negociações futuras, índices e classificações de países quanto à competitividade têm sido gerados levando em consideração uma centena de variáveis e as mais diversas metodologias. Em função da variedade de índices, não se sabe ao certo quais são os que melhor representam a realidade, já que os processos metodológicos publicados nos relatórios emitidos pelas instituições responsáveis são desprovidos de detalhes e precisão. Nesse sentido, obter reconhecimento de país competitivo em um determinado índice não implica o mesmo reconhecimento em outro índice da mesma natureza.

Os três principais índices de competitividade reconhecidos internacionalmente são o Índice de Competitividade Global (ICG), publicado pelo WEF, o World Competitiveness Yearbook (WCY), publicado pelo Institute for Management of Development (IMD), e o Índice de Desempenho Industrial (IDI), reportado pelo United Nations Industrial Development Organizations (Unido). Embora os três possuam reconhecimento internacional, o ICG, gerado pelo WEF, tem ganhado destaque pela sua composição estrutural, tamanho da amostra e periodicidade.

O WEF é uma organização internacional, independente, incorporada a uma organização sem fins lucrativos da Suíça. Os estudos do WEF partem do pressuposto de que o progresso econômico sem desenvolvimento social não é sustentável, enquanto o desenvolvimento social sem o progresso econômico não é viável. Para o WEF, a competitividade é derivada de uma série de instituições, políticas e fatores que determinam o nível de produtividade de um país. Baseado nisso, constituem-se 12 pilares de competitividade, divididos em três grupos, para empreender pesquisas enfocando a competitividade das nações. O grupo 1, denominado "Base da Economia", é constituído por: (a) instituições, (b) infraestrutura, (c) estabilidade macroeconômica e (d) saúde e educação primária. Já o grupo 2, denominado "Eficiência da Economia", é constituído por: (e) educação superior e treinamento, (f) eficiência do mercado de produtos, (g) eficiência do mercado de trabalho, (h) sofisticação do mercado financeiro, (i) prontidão tecnológica e (j) tamanho do mercado. Por fim, o grupo 3, denominado "Inovação da Economia", é formado por: (k) sofisticação de negócios e (1) inovação.

Apesar de esse agrupamento ser feito por áreas afins, entende-se que exista outra forma de agregar os referidos pilares para mensuração da competitividade e que a utilização dos pilares mais representativos de cada agrupamento, sob uma lógica baseada nos conceitos da análise multivariada, possa traduzir em melhores explicações a competitividade das nações, evitando redundância de medida entre os pilares. Baseado nesse entendimento, busca-se responder à seguinte pergunta de pesquisa: Considerando os fundamentos da estatística multivaria$\mathrm{da}$, quais alterações podem ser sugeridas quanto à estrutura e número de variáveis que compõem o índice de competitividade e de que forma essas alterações afetam sua análise? Dessa forma, lança-se a hipótese de que a utilização dos pilares mais significativos de cada agrupamento, com base na estatística multivariada, possa simplificar o modelo de análise e não alterar significativamente o ranking de competitividade dos países.

Para responder à pergunta de pesquisa e testar a hipótese, serão consideradas a correlação entre os pilares, a identificação dos constructos formados pelos pilares, a identificação dos pilares que melhor descrevem a condição competitiva dos países e a verificação de mudanças no ranking de competitividade dos países com base nesses pilares.

Os dados utilizados neste trabalho são oriundos dos relatórios publicados em 2010 pelo WEF após análise de 133 países. Os relatórios apresentam índices de competitividade para cada país participante e, em seguida, são classificados em forma de ranking.

\section{REFERENCIAL TEÓRICO}

Neste tópico, serão apresentados trabalhos que estabelecem conceitos de competitividade e utilizaram 
diversos constructos para análise da posição relativa das nações, bem como diferentes metodologias e fontes de bases de dados.

\section{Competitividade das nações}

A competitividade é fator relevante no crescimento e desenvolvimento de empresas e países. Dada a importância desse tema, Markusen (1987) alertou sobre a necessidade de uma definição clara e consistente que dê subsídios às ações nacionais e evite prejuízos às nações. Para essa afirmação, Markusen (1987) baseou-se no ocorrido na década de 1980, quando, segundo o autor, devido ao mau entendimento do conceito de competitividade, os Estados Unidos enfrentaram uma crise econômica derivada do baixo desempenho comercial, o que, para muitos analistas, significava a perda de competitividade. Nesse contexto, Markusen (1987) argumenta que o conceito de competitividade baseado no desempenho comercial pode gerar resultados opostos em comparação ao conceito de competitividade baseado na produtividade.

Embora com controvérsias apresentadas nos estudos de Makusen (1987), os estudos de Cas e outros (1988) apontam que a competitividade está associada ao desempenho comercial, seja da empresa ou do país. Nessa mesma linha, Rugman e D'Cruz (1989) corroboram que, se um país perde mercado exportador de um item ou de um setor, ou, ainda, aumenta a importação de produtos de um item ou um setor, por consequência, perde competitividade.

Sem discutir os conceitos até então existentes, Porter (1990) atém-se à definição de competitividade em um sentido mais abrangente e complexo, de modo que a competitividade é conceituada como a posição relativa de um país diante de seus concorrentes. Nesse contexto, a posição relativa mencionada por Porter (1990) diz respeito à discussão dos desempenhos das economias num senso de benchmarking, a fim de identificar as áreas da economia que estão menos desenvolvidas, sem se importar com os motivos que as levaram a tal (DUNNING, BANNERMAN, LUNDAN, 1998).

Com essa proposição, Dunning, Bannerman e Lundan (1998) buscaram estabelecer a posição relativa ou competitividade da nação por meio da análise do Produto Interno Bruto (PIB) per capita, já que constataram dificuldades de análise quando tentaram utilizar fatores que fossem além do PIB. Com base nessa análise, outros estudos avaliaram a competitividade nacional sob a mesma ótica (HEALEY \& BAKER, 1999; INTERVIEW, 1999).

Sob a perspectiva da eficiência operacional, a competitividade global é definida por Harrison (1995) como produto da tecnologia e da produção em escala: um país é competitivo se possui um nível médio de produtividade maior ou igual ao de seus concorrentes, ou, ainda, se tem um nível médio de custo unitário menor ou igual ao de seus concorrentes. A eficiência operacional, além de aumentar a competitividade, pode aumentar os resultados internos, e, sob esse aspecto, a OECD (1996) define competitividade como o grau com que um país, sob as condições do mercado, produz bens e serviços para um mercado internacional e simultaneamente mantém e aumenta as receitas do seu povo.

Estudos mais recentes, como o do IMD (2003), descrevem a competitividade como a capacidade relativa de um país criar e manter ambientes nos quais as empresas podem competir, gerando aumento do nível de prosperidade. Em consonância com esse ponto, o WEF apresenta uma das mais aceitas definições de competitividade, a qual é base deste trabalho. Para o WEF, a competitividade é representada por uma série de instituições, políticas e fatores que determinam o nível de produtividade de um país (WEF, 2010).

Embora a definição apresentada tenha aspecto macroeconômico, Schwab e Porter (2007) afirmam que existe um ponto em que aspectos macro são complementados pelos microeconômicos. O nível macro aumenta a oportunidade de produzir riqueza, a qual é gerada pela utilização de recursos humanos, capital e recursos naturais na produção de bens e serviços. A produção de bens e serviços, denominada produtividade, é dependente das condições microeconômicas das empresas em termos de qualidade e eficiência (SCHWAB E PORTER, 2007).

Com essas considerações, pode-se dizer que a competitividade apresenta diferentes aspectos de análise e acredita-se que, embora as definições apresentadas tenham bases diferentes, não se constituem excludentes, mas, sim, complementares.

\section{Métricas de competitividade}

O crescente aumento dos estudos e preocupação com a competitividade nacional deu-se com o advento da globalização e consequente abertura das economias, uma vez que as empresas passaram a competir em ambiente doméstico e internacional 
(PORTER, 1990). Assim, a competitividade das nações tem sido foco de investigação de consultorias e instituições de pesquisas como WEF, IMD e Unido, as quais desenvolveram conceitos e métricas para esse constructo. Os resultados obtidos das pesquisas gerados pelas instituições citadas servem de guia para tomadores de decisão na escolha de países que podem suscitar melhores retornos aos investimentos em função do desenvolvimento econômico e da competitividade internacional (ZANAKIS e BECERRA-FERNANDEZ, 2005).

Apesar de importantes, os relatórios dessas pesquisas por vezes são questionados, por não apresentarem resultados similares quando utilizam as mesmas amostras. Assim, Oral e Chabchoub (1996) discutem que os relatórios de competitividade publicados pelo IMD e WEF são carentes de informações precisas quando se referem à metodologia empregada, e as informações existentes são passíveis de diferentes interpretações. Berger e Bristow (2009) complementam ao afirmar que as diferenças de resultados podem ser geradas pela diversidade de variáveis e metodologias e épocas desiguais de condução das pesquisas.

A diversidade de variáveis na mensuração da competitividade nacional expressa por Berger e Bristow (2009) pode ser constatada por meio do Quadro 1, que apresenta a estrutura métrica utilizada pelas principais instituições de pesquisa em competitividade.

Conforme o Quadro 1, os índices gerados pelo IMD e WEF possuem similaridades de algumas variáveis, mas, embora haja alguma semelhança, os resultados não são compatíveis quando se referem à classificação dos países quanto ao seu grau de competitividade, conforme relatórios gerados em 2010 (WEF, 2010; IMD, 2011).

Apesar de não ser um índice de competitividade, Porter (1990) desenvolveu um modelo de análise para indústrias, denominado diamante. No modelo diamante, o sucesso internacional da nação em uma determinada indústria é dependente de quatro atributos que podem promover ou inibir a criação de vantagem competitiva: fatores condicionais (infraestrutura, recursos físicos,

\section{Quadro 1 - Variáveis pertencentes aos índices de competitividade}

\begin{tabular}{|c|c|c|}
\hline IMD & WEF & Unido \\
\hline $\begin{array}{l}\text { Desempenho econômico: } \\
\text { Economia doméstica; } \\
\text { Comércio internacional; } \\
\text { Investimento internacional; } \\
\text { Índice de empregos; } \\
\text { Índice de preços. } \\
\text { Eficiência do governo: } \\
\text { Finanças públicas; } \\
\text { Política fiscal; } \\
\text { Estrutura institucional; } \\
\text { Legislação para negócios; } \\
\text { Estrutura societária } \\
\text { Eficiência de negócios: } \\
\text { Produtividade; } \\
\text { Mercado de trabalho; } \\
\text { Finanças; } \\
\text { Práticas de gestão; } \\
\text { Atitudes e valores. } \\
\text { Infraestruturas: } \\
\text { Básicas; } \\
\text { Tecnológicas; } \\
\text { Científicas; } \\
\text { Saúde e ambiente; } \\
\text { Educacão. }\end{array}$ & $\begin{array}{l}\text { Base da economia: } \\
\text { Instituições; } \\
\text { Infraestrutura; } \\
\text { Estabilidade macroeconômica; } \\
\text { Saúde e educação primária. } \\
\text { Eficiência da economia: } \\
\text { Educação superior e treinamento; } \\
\text { Eficiência do mercado de produtos; } \\
\text { Eficiência do mercado de trabalho; } \\
\text { Sofisticação do mercado financeiro; } \\
\text { Prontidão tecnológica; } \\
\text { Tamanho do mercado. } \\
\text { Inovação da economia: } \\
\text { Sofisticação dos negócios; } \\
\text { Inovação. }\end{array}$ & $\begin{array}{l}\text { Valor adicionado dos produtos per capita; } \\
\text { Exportação de produtos per capita; } \\
\text { Intensidade de industrialização; } \\
\text { Qualidade da exportação. }\end{array}$ \\
\hline
\end{tabular}

Fonte: IMD.org, WEF.com e Unido.org. 
tecnologia etc.); concorrência, estrutura e estratégia da firma; indústrias de suporte e correlatas e condições da demanda. De acordo com o modelo diamante, a produção local, custos e qualidade dos fatores condicionais são considerados fundamentais para conferir vantagem competitiva efetiva na indústria, aumentando a competitividade do país.

Assim, devido à pluralidade de metodologias, variáveis e resultados, outros pesquisadores buscam entender a complexidade da competitividade e suas relações com elementos institucionais das nações (BUCKLEY, PASS, PRESCOTT, 1988). Esse é o caso de Dzeng e Wang (2008), que, com base nos dados do WCY, buscaram estudar a relação do desenvolvimento da infraestrutura com a competitividade das nações. Nesse estudo, os autores afirmam que a maioria dos relatórios gerados para analisar a competitividade dos países tem por base o desenvolvimento da infraestrutura e, dessa forma, o investimento em melhorias nas políticas para esse fim seria fator-chave para o desenvolvimento econômico e competitivo nacional.

Sob outra perspectiva, Zhao e Zhang (2007) utilizaram o índice de desempenho industrial das bases de dados da Unido para avaliar a posição competitiva da China no cenário internacional. As variáveis estudadas nesse índice levam em consideração as competências, esforços tecnológicos, investimentos diretos externos (FDI), infraestrutura moderna e pagamentos de royalties (variáveis inseridas nos pilares apresentados no Quadro 1). Verificou-se que a China deu um grande salto, em termos de competitividade industrial, devido a sua participação em redes internacionais de produção e que esse salto pode ser ainda maior, se houver investimentos em atualização e inovação industrial.

Já Gugler e Brunner (2007) descrevem as relações entre o FDI e a competitividade nacional e, ainda, afirmam que, embora o FDI tenha papel fundamental na competitividade, não se pode negligenciar a localização do país e o papel do cluster na capacidade absortiva do país hospedeiro de investimentos. Nessa mesma linha, Torres (2010) foca seu trabalho nos impactos gerados pelo recebimento de FDI sobre o desenvolvimento econômico e competitividade das nações no intuito de gerar uma matriz de valoração ou mensuração da relação. A matriz sugerida por Torres (2010) funciona como uma ferramenta pedagógica para o auxílio de países de menor desenvolvimento econômico na atração de investimentos externos e aumento da competitividade.
Estudos sobre o sistema nacional de inovação, investimentos em tecnologia e capital intelectual também foram considerados por Freeman (2004) como pilares da competitividade das nações. Considerou-se, ainda, que investimentos em educação, ciência, comércio e política industrial são complementares à construção dos pilares da competitividade.

De modo similar ao proposto no presente estudo, mas sem intenção de simplificar a metodologia de análise da competitividade, Zanakis e Becerra-Fernandez (2005) analisaram a base de dados do WCY, que engloba 55 variáveis e 43 países. Os resultados das análises revelaram que a competitividade da nação está relacionada ao baixo risco país, ao alto índice de uso de computadores, às sociedades empreendedoras com menor domínio masculino, ao alto investimento em infraestrutura, ao saldo da balança comercial e aos altos gastos em pesquisas e desenvolvimento (P\&D).

Embora os conceitos, métricas e perspectivas de análises possuam consideráveis diferenças, percebe-se que, entre os índices e trabalhos existentes, que há um senso comum que se refere à criação ou manutenção de um ambiente favorável à prosperidade da nação (KAO e outros, 2008).

\section{METODOLOGIA}

Este tópico apresenta a estrutura metodológica utilizada para atender aos objetivos da pesquisa quanto aos drivers da competitividade dos países e às questões expostas na introdução deste trabalho.

Para responder a tais perguntas, foi realizada uma pesquisa descritiva com método quantitativo, utilizando dados secundários das bases do WEF. Para Hair Jr. e outros (2005), os planos da pesquisa descritiva formam-se no intuito de medir características de um determinado construto teórico. No caso da presente pesquisa, essas características referem-se aos pilares da competitividade. Já o método quantitativo "se caracteriza pelo emprego de quantificação tanto nas modalidades de coleta de informações quanto no tratamento dessas informações por meio de técnicas estatísticas" (TEIXEIRA e PACHECO, 2005, p. 60).

Em primeiro plano, observaram-se os relatórios publicados pelo WEF em 2008, 2009 e 2010, e constatou-se que não houve alterações significativas nos escores de competitividade que justificassem a utilização dos três 
anos no estudo. Assim, optou-se por utilizar o ano de 2010, por ser o mais recente.

A escolha dos índices publicados pelo WEF deu-se pela sua estrutura métrica, periodicidade de publicação e, principalmente, pelo número de países envolvidos na pesquisa. Enquanto o IMD realizou pesquisas com 58 países, o WEF pesquisou 133 países. Já a Unido, que assume o índice de desenvolvimento industrial como base de competitividade, pesquisou 100 países.

As questões referentes aos 12 pilares do WEF tiveram opção de respostas escalonadas em sete pontos. Os 12 pilares foram divididos em três grupos e, ao final, foi gerado um índice que expressa o nível de competitividade do país (WEF, 2010).

Os 12 pilares descritos pelo WEF como representativos para a competitividade dos países e seus agrupamentos estão relacionados no Quadro 2.

Os dados foram tabulados e importados para o software estatístico SPSS v.19 para que pudesse ser realizada, em primeiro momento, a análise fatorial. A análise fatorial permite o agrupamento de variáveis que estão correlacionadas entre si e que estão relacionadas ao mesmo constructo (HAIR JR, 2005). A primeira rodada da análise considerou 12 fatores (o mesmo número de pilares a serem analisados), sem rotação, a fim de observar a distribuição das cargas fatoriais e o número de fatores significantes à variação total. Os pilares da competitividade foram agrupados nos fatores de acordo com a maior carga fatorial.

Por meio da análise de variâncias, foi identificado o número de fatores relevantes à variância total. Os fatores que contribuíram com $5 \%$ ou menos para a variância total foram considerados irrelevantes para o contexto. Após esse procedimento, foi realizada uma nova rodada na análise fatorial considerando apenas os fatores relevantes determinados em análise anterior, utilizando o método de rotação Varimax, que permite evidenciar as cargas das variáveis nos fatores às quais pertencem. Os fatores foram nomeados conforme os respectivos pilares constituintes, e os que obtiveram maior significância dentro de cada fator foram utilizados na equação da competitividade dos países participantes da amostra. Foram reconhecidos como relevantes os pilares que obtiveram as maiores cargas fatoriais dentro de cada fator e as maiores comunalidades entre eles.

Para garantir a robustez das análises, foi realizada regressão múltipla, com método stepwise, no intuito de identificar os pilares que possuíam o maior grau de explicação para os escores gerais apresentados pelo WEF.

Em seguida, por meio do método Best Subsets, foram geradas equações com um, dois e três pilares que teriam maior grau de explicação para a variável

\section{Quadro 2 - Pilares da competitividade}

\section{Grupo Pilar da competitividade}

1 - Instituições (institutions)

2 - Infraestrutura (infrastructure)

Base da economia
3 - Estabilidade macroeconômica (Macroeconomic stability)

4 - Saúde e educação primária (Health and primary education)

\section{Justificativa}

A qualidade das instituições influencia as decisões de investimentos e na organização da produção. As instituições têm papel relevante na forma como a sociedade distribui os lucros e arca com os custos de estratégias de desenvolvimento.

Infraestrutura bem desenvolvida reduz os efeitos da distância entre as regiões, com o resultado de uma verdadeira integração do mercado nacional, e conecta-0 a baixo custo a mercados de outros países e regiões.

Embora a estabilidade macroeconômica por si só não aumente a produtividade da nação, é reconhecido que um desarranjo macroeconômico prejudica a economia. 0 governo não pode prestar serviços de modo eficiente se tiver que fazer pagamentos de juros elevados sobre as suas dívidas passadas. As empresas não podem operar com eficiência quando as taxas de inflação estão fora de alcance.

Baixa assistência à saúde leva a custos significativos para as empresas; os trabalhadores doentes são, muitas vezes, ausentes ou operam em níveis mais baixos de eficiência. Trabalhadores que tiveram pouca instrução formal realizam trabalhos manuais mais simples e possuem dificuldades na adaptação de técnicas e processos de produção mais avançados. 


\section{Grupo Pilar da competitividade}

\section{5 - Educação superior e} treinamento (Higher education and training)

6 - Eficiência do mercado de produtos (Goods market efficiency)

7 - Eficiência do mercado de trabalho

(Labor market efficiency)

Eficiência da economia

\section{8 - Sofisticação do mercado financeiro (Financial market sophistication)}

9 - Prontidão tecnológica (Technological readiness)

10 - Tamanho do mercado (Market size)

\section{1 - Sofisticação de negócios} (Business sophistication)

Inovação da economia

\section{Justificativa}

A qualidade de ensino superior é crucial para as economias que querem subir na cadeia de valor para além dos processos de produção simples. A extensão da formação de pessoal também é levada em consideração, visto que é negligenciada em muitas economias para garantir uma atualização constante de competências dos trabalhadores às novas necessidades da economia em evolução.

Países com eficiência em mercados estão bem posicionados para produzir o mix correto de produtos e serviços para atendimento às condições de demanda, bem como para garantir que esses bens possam ser negociados de maneira mais eficaz na economia.

A eficiência e a flexibilidade do mercado de trabalho são fundamentais para garantir que os trabalhadores estejam alocados para a sua eficiente utilização na economia e incentivados a dar 0 seu melhor esforço em seus trabalhos. Assim, o mercado de trabalho eficiente deve também garantir uma clara relação entre os incentivos dos trabalhadores e seus esforços, bem como a melhor utilização dos talentos disponíveis, que inclui igualdade no ambiente de negócios entre homens e mulheres.

0 investimento empresarial é fundamental para produtividade. Assim, as economias requerem sofisticados mercados financeiros que podem tornar 0 capital disponível para investimentos do setor privado com base em fontes tais como empréstimos do setor bancário, bolsas de valores, capital de risco e outros produtos financeiros.

Refere-se à agilidade com que a economia adota as tecnologias existentes para melhorar a produtividade da sua indústria. No mundo globalizado, a tecnologia tem se tornado um elemento importante para as empresas para competir e prosperar. Em particular, a tecnologia de informação e comunicação (TIC) tem evoluído para a "tecnologia de uso geral" do nosso tempo, tendo em conta as repercussões importantes para o desenvolvimento econômico de outros setores e o seu papel como infraestrutura eficiente para transações comerciais.

0 tamanho do mercado afeta a produtividade, uma vez que os mercados de grandes empresas permitem explorar as economias de escala. Tradicionalmente, os mercados disponíveis para as empresas têm sido limitados pelas fronteiras nacionais. $\mathrm{Na}$ era da globalização, os mercados internacionais tornaram-se um substituto para 0 mercado interno, especialmente para os pequenos países.

A sofisticação de negócios é propícia a uma maior eficiência na produção de bens e serviços. Esta leva, por sua vez, ao aumento da produtividade, aumentando, assim, a competitividade de uma nação. A sofisticação de negócios refere-se à qualidade das redes globais de negócio do país, bem como à qualidade das estratégias de operações individuais das empresas.

A inovação requer um ambiente que favorece a atividade inovadora, apoiada tanto pelo setor público como pelo privado. Isso significa um importante investimento em pesquisa e desenvolvimento (P\&D), especialmente pelo setor privado, presença da alta qualidade das instituições de pesquisa científica, extensa colaboração em pesquisa entre universidades e indústria, bem como a proteção da propriedade intelectual.

Fonte: World Economic Forum (2010)

resposta (escore geral). Ao final, gerou-se uma tabela comparativa entre a classificação publicada pelo WEF e a proposta pelos autores do presente trabalho. Com essas análises, puderam-se testar as hipóteses que estão em consonância com a pergunta de pesquisa deste trabalho. As hipóteses seguem: 
H0: A identificação e utilização dos pilares mais significativos, entre os 12 pilares propostos pelo WEF para análise da competitividade do país, não alteram significativamente o ranking de classificação dos países.

H1: A identificação e utilização dos pilares mais significativos, entre os 12 pilares propostos pelo WEF para análise da competitividade do país, alteram significativamente o ranking de classificação dos países.

Os dados foram apresentados em tabelas, quadros e gráficos para facilitar o entendimento da análise.

\section{ANÁLISE DOS DADOS}

Para o cumprimento dos objetivos propostos neste trabalho, os dados secundários oriundos dos relatórios do WEF foram considerados em sua totalidade, ou seja, todos os 12 pilares que compõem o índice de competitividade global foram avaliados sem levar em conta os agrupamentos nos quais foram classificados originalmente.

Para constatação do constructo formado pelos 12 pilares, foi realizada a análise fatorial. As cargas fatoriais e a alocação dos pilares em fatores são demonstradas por meio da Tabela 1.

Pode-se observar que as variáveis em estudo estão altamente correlacionadas e, em sua maioria, pertencem ao Fator 1, o qual possui 69,4\% de influência sobre a variância geral. Os Fatores 2 e 3 possuem menores influências, sendo 8,5\% e 6,4\%, respectivamente. Assim, os três primeiros fatores apresentam grande significância sobre a variância total.

Para que as variáveis apresentassem cargas fatoriais mais bem evidenciadas nos fatores às quais pertencem, foi gerada uma nova matriz fatorial com limitação de três fatores e com método de rotação Varimax. Por meio da nova distribuição, apresentada na Tabela 2,

\section{Tabela 1 - Distribuição fatorial das variáveis de competitividade do WEF}

\begin{tabular}{|c|c|c|c|c|c|c|c|c|c|c|c|c|}
\hline Variáveis & 1 & 2 & 3 & 4 & 5 & 6 & 7 & 8 & 9 & 10 & 11 & 12 \\
\hline Instituição & 0,877 & $-0,301$ & 0,146 & 0,031 & 0,163 & 0,156 & $-0,112$ & 0,141 & $-0,171$ & $-0,038$ & $-0,014$ & 0,06 \\
\hline Infra & 0,925 & $-0,034$ & $-0,025$ & 0,062 & 0,119 & 0,19 & $-0,173$ & $-0,233$ & $-0,003$ & 0,038 & 0,009 & $-0,048$ \\
\hline Estab_macro & 0,493 & 0,338 & 0,799 & 0,02 & $-0,033$ & 0,011 & 0,04 & $-0,006$ & 0,022 & 0,026 & 0,008 & $-0,003$ \\
\hline Saude_edu_bas & 0,759 & 0,237 & $-0,138$ & 0,532 & $-0,112$ & $-0,168$ & $-0,09$ & 0,083 & 0,01 & 0,087 & $-0,046$ & $-0,004$ \\
\hline Edu_superior & 0,925 & 0,097 & $-0,108$ & 0,242 & $-0,102$ & 0,009 & 0,132 & $-0,025$ & $-0,079$ & $-0,096$ & 0,142 & $-0,022$ \\
\hline Mercado & 0,936 & $-0,152$ & 0,026 & $-0,109$ & 0,112 & $-0,069$ & $-0,092$ & 0,132 & 0,174 & $-0,087$ & 0,02 & $-0,085$ \\
\hline Merc_trab & 0,699 & $-0,46$ & 0,095 & $-0,17$ & $-0,486$ & $-0,135$ & $-0,062$ & $-0,046$ & $-0,004$ & 0,008 & 0,001 & 0,022 \\
\hline Merc_finan & 0,829 & $-0,198$ & 0,021 & $-0,12$ & 0,291 & $-0,389$ & 0,101 & $-0,065$ & $-0,074$ & 0,051 & $-0,013$ & $-0,012$ \\
\hline Tecnologia & 0,958 & 0,015 & $-0,05$ & 0,116 & 0,006 & 0,06 & 0,122 & $-0,083$ & 0,08 & $-0,121$ & $-0,124$ & 0,061 \\
\hline Tam_mercado & 0,574 & 0,682 & $-0,175$ & $-0,37$ & $-0,08$ & $-0,102$ & $-0,105$ & 0,006 & $-0,081$ & $-0,053$ & $-0,019$ & 0,009 \\
\hline Sof_negócios & 0,944 & 0,081 & $-0,144$ & $-0,149$ & 0,079 & 0,075 & 0,026 & 0,026 & 0,13 & 0,104 & 0,08 & 0,11 \\
\hline Inovação & 0,913 & 0,004 & $-0,128$ & $-0,174$ & $-0,106$ & 0,233 & 0,162 & 0,076 & $-0,047$ & 0,097 & $-0,055$ & $-0,083$ \\
\hline Variância & 8,3253 & 1,0175 & 0,7712 & 0,6049 & 0,422 & 0,3367 & 0,1453 & 0,119 & 0,104 & 0,0682 & 0,0486 & 0,0371 \\
\hline Var & 0,694 & 0,085 & 0,064 & 0,04 & 0,035 & 0,028 & 0,012 & 0,01 & 0,009 & 0,006 & 0,004 & 0,003 \\
\hline Var acumulada & 0,694 & 0,779 & 0,843 & 0,893 & 0,928 & 0,956 & 0,968 & 0,978 & 0,987 & 0,993 & 0,997 & 1 \\
\hline
\end{tabular}

Fonte: Dados da pesquisa. 
apenas um pilar (Saúde e Educação Básica) obteve carga fatorial substancialmente modificada que o categorizou em outro fator; os demais preservaram seus fatores de origem.

Fazem parte do Fator 1 os pilares: Instituição, Infraestrutura, Educação Superior, Eficiência do Mercado de Produtos, Eficiência do Mercado de Trabalho, Eficiência do Mercado Financeiro, Prontidão Tecnológica, Sofisticação de Negócios e Inovação. O segundo fator foi caracterizado pelos pilares Saúde e Educação Básica e Tamanho do Mercado. Já o fator 3 foi caracterizado isoladamente pelo pilar Estabilidade Macroeconômica.

Em comparação ao agrupamento dos pilares proposto pelo WEF, observa-se que este não levou em consideração as correlações existentes entre as variáveis, mas, sim, as áreas afins, ou seja, o grupo "melhoria de eficiência" reuniu variáveis relacionadas ao desempenho do mercado de produtos, do mercado de trabalho, do mercado financeiro, do ensino superior etc., independentemente da correlação existente entre elas ou do constructo o qual essas variáveis em conjunto pudessem representar. Sendo assim, verifica-se uma redundância de variáveis ao representar o mesmo constructo que pode ser prejudicial à construção de um modelo preditivo de competitividade internacional.

Os Fatores 1, 2 e 3 apresentados na análise fatorial podem ser nominados de acordo com as variáveis que os constituem, tais como: Ambiente de Negócios, Base da Economia e Estabilidade Macroeconômica, respectivamente, conforme Quadro 3.

De acordo com os dados apresentados na Tabela 2 e no Quadro 1, pode-se afirmar que a maioria das variáveis possui constructo comum; isso significa dizer que alteração de carga em um pilar da competitividade implica significativas alterações nos demais pilares e que, em termos de métrica, há violação do princípio referente à ausência de multicolinearidade entre as variáveis independentes.

Dessa forma, buscou-se destacar os pilares que pudessem representar os constructos a fim de simplificar a análise de competitividade dos países. Para isso, foi traçada a matriz de correlação dos constituintes dos fatores, no intuito de se obter aquele com a maior média de correlação entre os demais, conforme Tabela 3.

Por meio da Tabela 3, podem-se identificar os pilares Prontidão Tecnológica e Sofisticação de Negócios como os que possuem maior correlação média com o grupo fatorial ao qual pertencem, sendo estas $76,2 \%$ e 74,9\%, respectivamente. Essa informação também pode ser confirmada por meio da Tabela 2 , em que a comunalidade dessas duas variáveis dentro do Fator 1 é a mais representativa. Isso significa dizer que a

\section{Tabela 2 - Distribuição fatorial das variáveis de competitividade do WEF - Método Varimax}

\begin{tabular}{|l|c|c|c|c|}
\hline \multicolumn{1}{|c|}{ Variáveis } & $\mathbf{1}$ & $\mathbf{2}$ & $\mathbf{3}$ & Comunalidade \\
\hline Instituição & 0,888 & 0,204 & 0,882 \\
\hline Infra & 0,765 & 0,494 & 0,227 & 0,858 \\
\hline Estab_macro & 0,213 & 0,206 & 0,168 & 0,996 \\
\hline Saude_edu_bas & 0,469 & 0,647 & 0,953 & 0,652 \\
\hline Edu_superior & 0,685 & 0,623 & 0,117 & 0,877 \\
\hline Mercado & 0,845 & 0,393 & 0,71 \\
\hline Merc_trab & 0,838 & 0,009 & 0,179 & 0,727 \\
\hline Merc_finan & 0,785 & 0,302 & 0,089 & 0,921 \\
\hline Tecnologia & 0,762 & 0,136 & 0,825 \\
\hline Tam_mercado & 0,055 & 0,858 & 0,169 & 0,918 \\
\hline Sof_negócios & 0,71 & 0,635 & 0,101 & 0,85 \\
\hline Inovação & 0,731 & 0,556 & 0,083 & 10,114 \\
\hline Variância & 5,763 & 3,1922 & 1,1588 & 0,843 \\
\hline \% Var & 0,48 & 0,266 & 0,097 & \\
\hline
\end{tabular}

Fonte: Dados da pesquisa. 
variabilidade destas é explicada em 92,1\% e 91,8\% pelos três fatores ou, ainda, que existe um alto grau de correlação dessas variáveis com as demais, principalmente com aquelas do fator ao qual pertencem. Dadas essas considerações, acredita-se que os pilares Prontidão Tecnológica e Sofisticação de Negócios sejam os mais representativos no Fator 1 - Ambiente de Negócios.
A análise do Fator 2, que congrega os pilares Tamanho de Mercado e Saúde e Educação Básica, apresenta aspecto diferenciado do Fator 1, já que a correlação entre esses dois pilares é baixa (45,6\%), e comunalidades de $82,5 \%$ e $65,2 \%$, respectivamente. Em termos comparativos, pode-se dizer que essas variáveis não apresentam grau de explicação relevante ao constructo formado e que a variabilidade destas é relativamente

\section{Quadro 3 - Classificação das variáveis quanto ao modelo do WEF e o modelo proposto}

\begin{tabular}{|c|c|c|c|}
\hline Variáveis & WEF & Variáveis & Classificação dos autores \\
\hline $\begin{array}{l}\text { Instituição } \\
\text { Infraestrutura }\end{array}$ & \multirow{2}{*}{$\begin{array}{l}\text { Fatores básicos } \\
\text { dirigentes } \\
\text { Das economias }\end{array}$} & $\begin{array}{l}\text { Tamanho do mercado } \\
\text { Saúde e educação básica }\end{array}$ & Base da economia \\
\hline $\begin{array}{l}\text { Estabilidade macroeconômica } \\
\text { Saúde e educação básica }\end{array}$ & & $\begin{array}{l}\text { Estabilidade macroeconômica } \\
\text { Instituição }\end{array}$ & Estabilidade macroeconômica \\
\hline $\begin{array}{l}\text { Educação superior e treinamento } \\
\text { Eficiência do mercado de produtos } \\
\text { Eficiência do mercado de trabalho } \\
\text { Sofisticação do mercado financeiro } \\
\text { Prontidão tecnológica } \\
\text { Tamanho do mercado }\end{array}$ & $\begin{array}{l}\text { Fatores de melhoria } \\
\text { De eficiência da } \\
\text { economia }\end{array}$ & $\begin{array}{l}\text { Infraestrutura } \\
\text { Educação superior e treinamento } \\
\text { Eficiência do mercado de produtos } \\
\text { Eficiência do mercado de trabalho } \\
\text { Sofisticação do mercado financeiro } \\
\text { Prontidão tecnológica }\end{array}$ & \multirow[t]{2}{*}{ Ambiente de negócios } \\
\hline $\begin{array}{l}\text { Sofisticação dos negócios } \\
\text { Inovação }\end{array}$ & $\begin{array}{l}\text { Fatores inovadores } \\
\text { Da economia }\end{array}$ & $\begin{array}{l}\text { Sofisticação dos negócios } \\
\text { Inovação }\end{array}$ & \\
\hline
\end{tabular}

Fonte: Dados da pesquisa

\section{Tabela 3 - Matriz de correlação das variáveis do fator 1}

\begin{tabular}{|c|c|c|c|c|c|c|c|c|}
\hline Variáveis & 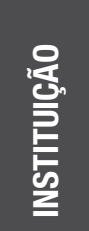 & $\frac{\underline{x}}{\frac{\alpha}{2}}$ & 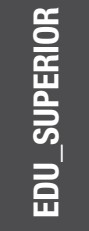 & $\begin{array}{l}0 \\
\frac{0}{0} \\
\frac{1}{1} \\
\frac{1}{2}\end{array}$ & 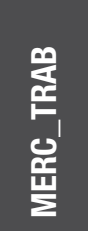 & 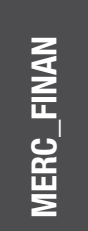 & 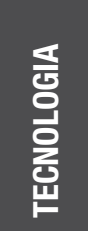 & $\begin{array}{l}\text { 웅 } \\
\text { 언 } \\
\text { 픈 } \\
\text { ㄴㅇㅇ }\end{array}$ \\
\hline Infra & 0,851 & & & & & & & \\
\hline Edu_superior & 0,754 & 0,842 & & & & & & \\
\hline Mercado & 0,872 & 0,849 & 0,793 & & & & & \\
\hline Merc_trab & 0,662 & 0,587 & 0,591 & 0,697 & & & & \\
\hline Merc_finan & 0,763 & 0,727 & 0,697 & 0,845 & 0,601 & & & \\
\hline Tecnologia & 0,814 & 0,896 & 0,926 & 0,872 & 0,624 & 0,761 & & \\
\hline Sof_negócios & 0,783 & 0,877 & 0,844 & 0,894 & 0,586 & 0,769 & 0,896 & \\
\hline Inovação & 0,788 & 0,83 & 0,837 & 0,826 & 0,66 & 0,675 & 0,874 & 0,912 \\
\hline
\end{tabular}

Fonte: Dados da pesquisa. 
baixa, se comparada à das demais variáveis. Portanto, não se pode afirmar com clareza qual a significância dessas variáveis para a simplificação do modelo de análise de competitividade dos países.

Analisando o último fator, que é caracterizado pela Estabilidade Macroeconômica, verifica-se que a variabilidade desse indicador está altamente correlacionada com os três fatores $(99,6 \%)$, conforme consta na Tabela 2.

Para garantir a confiabilidade e robustez na análise dos dados no que se refere à escolha de variáveis significantes à determinação do escore de competitividade dos países, foi realizada regressão múltipla, com método Best Subsets, com todas as 12 variáveis denominadas pilares da competitividade. Esse método possibilita achar a melhor combinação entre as variáveis independentes que explique o escore de competitividade dos países, realizando testes desde uma até 12 variáveis em conjunto. As combinações mais significativas são demonstradas na Tabela 4.

De acordo com a Tabela 4, pode-se destacar que a Prontidão Tecnológica é responsável por $86,5 \%$ da competitividade dos países. Embora significativo, não se pode determinar o índice de competitividade global apenas pela análise dessa variável, já que o erro preditivo é de $13,5 \%$. De acordo com o WEF, a prontidão tecnológica de um país refere-se à agilidade com que este adota ou cria novas tecnologias para garantir a melhoria da produtividade de suas indústrias, tornando-se um elemento importante para que as empresas possam competir e prosperar (WEF, 2010).

Observa-se, ainda, que o grau de explicação da competitividade do país aumenta ao combinar a variável Sofisticação dos Negócios e a Estabilidade Macroeconômica, as quais, juntas, respondem por $91,4 \%$ do índice global. Esses resultados estão de acordo com os estudos de Zanakis e Becerra-Fernandes (2005), os quais apontaram que o baixo risco-país e investimentos em infraestrutura refletem na estabilidade macroeconômica, que, por sua vez, atrai investimentos externos, aumentando a competitividade do país (ZANAKIS e BECERRA-FERNANDEZ, 2005; GUGLER e BRUNNER, 2007; TORRES, 2010). Nesse sentido, diz-se que a estabilidade macroeconômica assume papel mediador entre as ações governamentais para desenvolvimento do país (tais como geração de emprego e renda, controle inflacionário, aumento de produção e incentivo ao comércio internacional) e a competitividade. Nessa análise, verificou-se, ainda, que a inclusão da variável Educação Superior confere $4,3 \%$ de acréscimo ao poder de explicação da variável dependente e que o erro de previsão do índice de competitividade global cai para 4,3\%. A qualidade do ensino também pôde ser evidenciada nos estudos de Freeman (2004) como um dos pilares da competitividade, em que investimentos em educação, ciência e tecnologia aumentam o nível do capital intelectual, que gera desempenho superior na execução de negócios.

\section{Tabela 4 - Coeficiente de determinação das melhores combinações de variáveis}

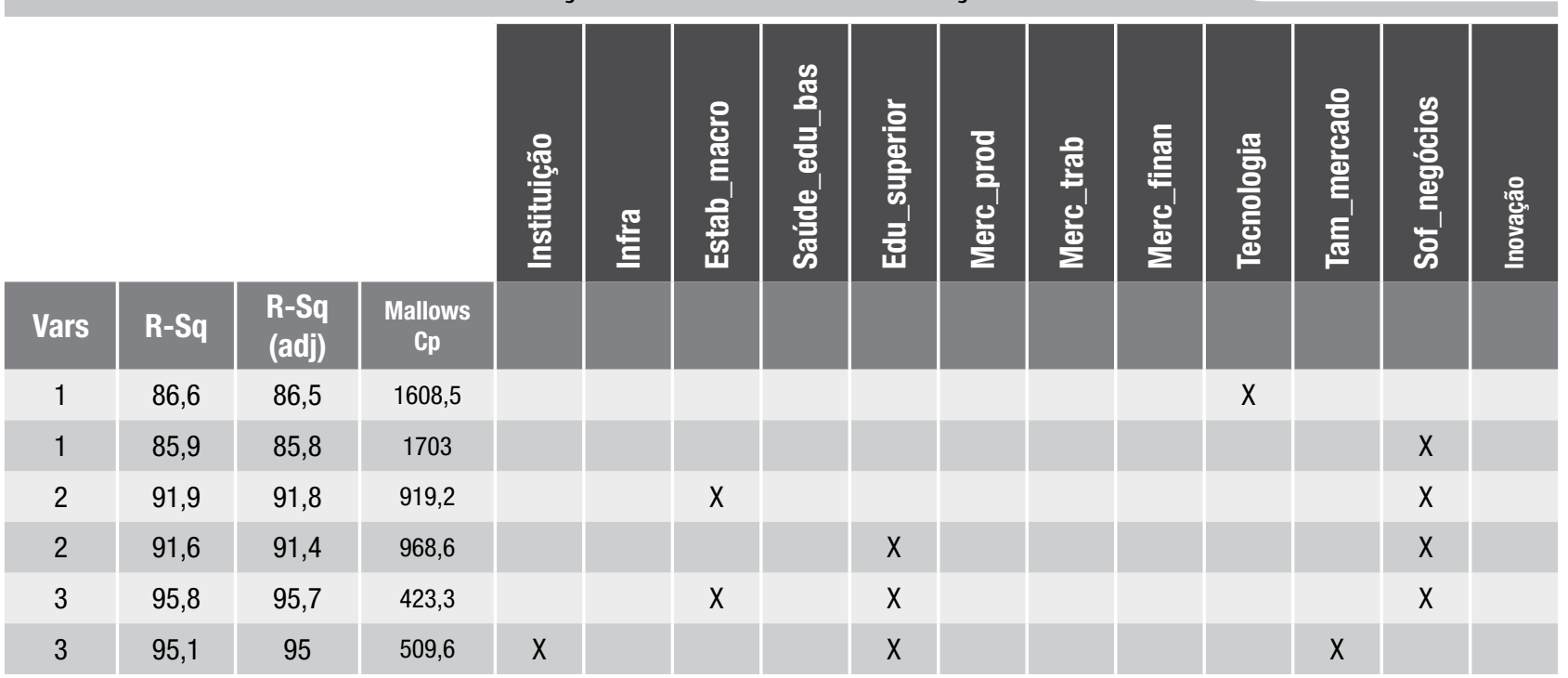

Fonte: Dados da pesquisa. 
Em relação aos dados, destaca-se que as demais combinações não aumentam significantemente o grau de explicação do índice, sendo, assim, denominados complementares, mas não básicos para a competitividade dos países.

Com base nessas considerações, pôde-se determinar a equação de regressão que apresenta maior capacidade preditiva sobre os escores de competitividade global. A equação é demonstrada a seguir:

ESCORE $=0,328+0,163$ ESTAB_MACRO $+0,275$
EDU_SUPERIOR $+0,482$ SOF_NEGÓCIOS

Em que:

ESCORE: Índice de Competitividade Global

ESTAB_MACRO: Estabilidade Macroeconômica

EDU_SUPERIOR: Qualidade do Ensino Superior e

Treinamentos

SOF_NEGÓCIOS: Sofisticação dos Negócios

A equação da regressão apresentou teste de significância com P-value $=0,00, \mathrm{~T}>10,82, \mathrm{~F}=974,11 \mathrm{e}$ VIF's $<3,61$, que são considerados satisfatórios para objetivos métricos. Analisando a equação, observa-se que a variável Sofisticação de Negócios possui maior peso no modelo preditivo, já que, mantidas as demais variáveis constantes, a variação de uma unidade do pilar Sofisticação de Negócios altera a competitividade em 0,48 , o que significa uma influência de $48 \%$.

\section{Quadro 4 - Comparativo da classificação dos países quanto ao índice de competitividade global}

\begin{tabular}{|c|c|c|}
\hline Classificação & WEF & Autores \\
\hline $1^{\circ}$ & Suíça & Suíça \\
\hline $2^{\circ}$ & Estados Unidos & Suécia \\
\hline $3^{\circ}$ & Singapura & Dinamarca \\
\hline $4^{\circ}$ & Suécia & Finlândia \\
\hline $5^{\circ}$ & Dinamarca & Alemanha \\
\hline $6^{\circ}$ & Finlândia & Holanda \\
\hline $7^{\circ}$ & Alemanha & Estados Unidos \\
\hline $8^{\circ}$ & Japão & Áustria \\
\hline $9^{\circ}$ & Canadá & Noruega \\
\hline $10^{\circ}$ & Holanda & Japão \\
\hline Brasil & $56^{\circ}$ & $53^{\circ}$ \\
\hline
\end{tabular}

Fonte: Dados da pesquisa.
Os escores das variáveis selecionadas foram substituídos na equação e um novo escore geral foi formado. Dessa forma, a comparação entre a classificação dos países quanto à competitividade global dada pelo WEF e a proposta por este estudo segue conforme Quadro 3.

Pode-se dizer que, embora se tenha utilizado métodos distintos para a classificação, não há considerável variação de escores que possa gerar dúvidas quanto à competitividade do país, mas há reposicionamento de classificação. Com base nas análises anteriores, não se rejeita a hipótese nula e, por exclusão, rejeita-se a hipótese alternativa. Assim, assume-se que a identificação e utilização dos pilares mais significativos, entre os 12 pilares propostos pelo WEF para análise da competitividade do país, não alteram significativamente o ranking de classificação dos países (hipótese nula).

O reposicionamento dos países na classificação dá-se principalmente pela medição única de cada constructo. Os Estados Unidos, que antes ocupavam a segunda colocação no ranking do WEF, passam a ocupar a sétima colocação pela métrica proposta. A alteração é justificada pelos altos valores que o país possui para os nove pilares pertencentes ao Fator 1 - Ambiente de Negócios, e devido à alta correlação entre os pilares constituintes desse fator (alto valor em um pilar significa alto valor nos oito demais pilares do mesmo fator). Da mesma forma, um país que apresenta baixo escore em um pilar pertencente ao Fator 1, consequentemente, apresenta baixo valor nos oito demais pilares desse fator. Ressalta-se que a consideração de todos os pilares pertencentes ao mesmo fator para fins preditivos ou métricos fere os princípios da ausência de multicolinearidade, ocasionando resultados dúbios para análise.

\section{CONCLUSÃO}

Em atendimento às questões norteadoras da pesquisa, buscou-se, por meio de análises estatísticas, entender as relações entre as variáveis que compõem os índices de competitividade das nações desenvolvidos pelo WEF e sugerir uma simplificação do modelo de modo que evite resultados dúbios quando da utilização de pilares que estão altamente correlacionados.

Em primeira análise, verificou-se que nove das 12 variáveis estavam altamente correlacionadas e que, juntas, formariam o constructo Ambiente de Negócios. Com isso, pode-se admitir que os agrupamentos de propostos pelo WEF não seguem uma 
lógica de constructo, mas, sim, de variáveis que compõem uma determinada área sem, necessariamente, haver relação entre elas. Com essas considerações, pode-se dizer que a métrica utilizada pelo WEF, que considera todos os nove pilares de um mesmo fator, é redundante, ou seja, todas as variáveis medem o mesmo constructo e, dessa forma, a utilização desses pilares favorece países que apresentam maior desenvolvimento econômico. Essa afirmação pode ser confirmada por meio do Quadro 3, em que os Estados Unidos caíram cinco colocações quando se utilizou a métrica por constructo.

Sendo assim, este estudo encontrou três grandes grupos formadores da competitividade das nações: Ambiente de Negócio, Base da Economia e Estabilidade Macroeconômica. Esses constructos foram representados pelos seus pilares mais significativos e, por meio da análise de regressão com método Best Subsets, encontrou-se a equação com os três pilares que, juntos, explicam o escore dado pelo WEF em 95,7\%. As variáveis mais representativas são: Estabilidade Macroeconômica, Qualidade do Ensino Superior e Sofisticação dos Negócios.

Os pilares do Fator 2 - Base da Economia não foram significativos a ponto de representar um constructo e, dessa forma, a equação utilizou dois pilares do Fator 1 que apresentaram maior correlação média com os pilares do mesmo fator e que, ao mesmo tempo, apresentaram considerável grau de independência entre eles.

Com as variáveis em questão, verificou-se que não há mudanças significativas que questionem a competitividade das nações, mas que há alteração no ranking de competitividade por diferenças em escores. Com isso, afirma-se que apenas as três variáveis destacadas seriam suficientes para determinar a competitividade dos países.

Ressalta-se que o estudo apresenta limitações quanto a informações metodológicas para a formação do escore de competitividade, uma vez que as publicações do WEF não expressam claramente os processos realizados.

Considera-se relevante a ampliação deste estudo em termos de estabelecimento de relações causais dos pilares da competitividade, agregando novas variáveis oriundas de bases de dados governamentais a fim de auxiliar os tomadores de decisão e governantes públicos quanto aos investimentos necessários em áreas da economia que podem alavancar o poder competitivo das nações.

\section{REFERÊNCIAS}

BERGER, T; BRISTOW, G. Competitiveness and the benchmarking of nations: a critical reflection. International Advances in Economic Research, v. 15, n. 4, p. 378-392, 2009 .

BUCKLEY, P. J; PASS, C. L; PRESCOTT, K. Measure of international competitiveness: a critical survey. Journal of Marketing Management, v. 4, n. 2, p. 175-200, 1988.

CAS, A. e outros. Productivity growth and changes in terms of trade in Canada. In: Freenstra, R. (Ed). Empirical methods for international economics. Cambridge: MIT Press, 1988. p. 279-294.

DUNNING, J; BANNERMAN E; LUNDAN S. M. Competitiveness and industrial policy in Northern Ireland. Monograph, Northern Ireland Research Council, 1998.

DZENG, R.-J; WANG, S. S. An analysis of infrastructure development based on national competitiveness perspectives. Construction Management and Economics, v. 26, n. 1, p. 47-61, 2008.

FREEMAN, C. Technological infrastructure and international competitiveness. Industrial and Corporate Change, v. 13, n. 3, p. 541-569, 2004.

GUGLER, P; BRUNNER, S. FDI effects on national competitiveness: a cluster approach. International Advances in Economic Research, v. 13, n. 3, p. 268-284, 2007.

HAIR JR, J. F. e outros. Fundamentos de métodos de pesquisa em administração. Porto Alegre: Bookman, 2005.

HARRISON, F. E. Canada's global competitiveness challenge: trade performance versus total factor productivity measures. American Journal of Economics and Sociology, v. 54, n. 1, p. 57-78, 1995.

HEALEY \& BAKER. European cities monitor: Europe's top cities. London: Healey \& Baker, 1999.

IMD. World competitiveness yearbook 2003. Institute for Management Development, Lausanne, 2003.

IMD. World competitiveness yearbook 2011. Disponível em: http://www.imd.ch/wcy/. Acesso em 15.02.2011. 
INTERVIEW. The competitive advantage of the major cities in Europe. INTERVIEW, Amsterdam, 1999.

$\mathrm{KAO}$, C. e outros. Measuring the national competitiveness of Southeast Asian countries. European Journal of Operational Research, v. 187, p. 613-628, 2008.

MARKUSEN, J, R. U.S. Canada free trade: effects on welfare and sectorial output/employment levels in the short and long run. Washington: U. S. Department of Labor, 1987.

OECD. Industrial competitiveness: benchmarking business environment in the global economy. OECD: Paris, 1996.

ORAL, M; CHABCHOUB, H. On the methodology of the world competitiveness report. European Journal of Operational Research, v. 90, n. 3, p. 514-535, 1996.

PORTER, M. E. The competitive advantage of nations. London: Macmillan, 1990.

RUGMAN, A; D'CRUZ, J. Fast forward: improving Canada's International Toronto. Toronto: Faculty of Management, University of Toronto, 1989.

SCHWAB, K; PORTER, M. E. The global competitiveness report 2007-2008. World Economic Forum, Geneva, 2007.

TEIXEIRA, R. de F; PACHECO, M. E. C. Pesquisa social e a valorização da abordagem qualitativa no curso de administração: a quebra de paradigmas científicos. Cadernos de Pesquisa em Administração, v. 12, n. 1, p. 55-68, 2005.

TORRES, C. R. Inversión extranjera y competitividad. Review Literature and Arts of the Americas, v. 4, n 2, p. 72-87, 2010.

UNIDO. Annual Repport 2011. Disponível em: http://www. unido.org/. Acesso em 01.02.2011.

WEF. Global competitiveness index 2010. World Economic Forum, Geneva, 2010.

WEF. The Global Competitiveness Report 2010-2011. Disponível em: http://www.weforum.org. Acesso em 15.02.2011.

ZANAKIS, S; BECERRA-FERNANDEZ, I. Competitiveness of nations: a knowledge discovery examination. European Journal of Operational Research, v. 166, n. 1, p. 185$211,2005$.
ZHAO, Z; ZHANG, K. H. China's industrial competitiveness in the world. The Chinese Economy, v. 40, n. 6, p. 6-23, 2007. 